\title{
Dielectric and Dynamic Mechanical Behaviour of Poly(vinyl chloride) Containing Small Amounts of Cholesterol, Cholesteryl Chloride, and Cholesteryl Benzoate
}

\author{
D. D. DeshPANDE* and V. K. TIWARI \\ Polymer Research Laboratory, Department of Chemistry, \\ Indian Institute of Technology, Bombay, \\ Powai, Bombay 400 076, India
}

(Received December 3, 1982)

\begin{abstract}
Poly(vinyl chloride) (PVC) containing small amounts of cholesterol (Ch), cholesteryl chloride $(\mathrm{ChCl})$, and cholesteryl benzoate $(\mathrm{ChBz})$ were studied by dielectric and dynamic mechanical spectrometry. Dielectric data were fitted to the WLF equation. Using the $\mathrm{C}_{1}$, $\mathrm{C}_{2}$ constants obtained for pure PVC, PVC+additive systems fitted well the WLF curve by an appropriate choice of reference temperature, $T_{0} . T_{0}$ of PVC + additives were lower than that of pure PVC. $\alpha$ - and $\beta$-peaks in PVC + additives occurred at temperatures lower than those in pure PVC. $\beta$ Peak intensities in DMA spectra decreased on adding $\mathrm{Ch}$ and $\mathrm{ChBz}$. This may be ascribed to the possible specific interactions of $\mathrm{C}-\mathrm{Cl}$ dipoles in $\mathrm{PVC}$ with $\mathrm{OH}$ from $\mathrm{Ch}$ or aromatic protons from $\mathrm{ChBz}$. Such a suppression of $\beta$-peak is described as antiplasticization by earlier workers. The behaviour of these additives with PVC differed from that with poly(vinyl acetate) or poly(butyl methacrylate) due to differences in apparent enthalpy of activation $\left(\Delta H_{\mathrm{a}}\right)$ for the $\alpha$-process.

KEY WORDS Dielectric Behaviour / Poly(vinyl chloride) Systems /

Cholesteryl Compounds / Dynamic Mechanical Analysis /
\end{abstract}

In our earlier studies ${ }^{1-3}$ we reported the dielectric behaviour of poly(vinyl acetate) (PVAc) and $\operatorname{poly}(n$-butyl methacrylate) (PBMA) containing small concentrations of cholesteryl liquid crystalline compounds. The shift of the $\alpha$-relaxation peak in these polymers to high temperatures and low frequency has been attributed to the antiplasticizing effect of cholesteryl compounds. In this paper, we report on the dielectric and dynamic mechanical behaviour of poly(vinyl chloride) (PVC) containing small amounts of cholesterol, cholesteryl chloride and cholesteryl benzoate.

In PVAc and PBMA, the dipoles are located in flexible groups pendant to the main chain. In contrast, the $\mathrm{C}-\mathrm{Cl}$ dipole in $\mathrm{PVC}$ is rigidly attached to the main chain. Further, the three additives used here are crystalline compounds at room temperature, with the crystal $\rightarrow$ isotropic liquid transition temperature higher than the glass transition temperature of PVC.

\section{EXPERIMENTAL}

\section{Materials}

A suspension polymerized PVC and having a viscosity average molecular weight of 85,000 was washed with methanol to remove any soluble impurities and additives. It was further washed with hot benzene to remove low molecular weight fractions and dried in vacuo. Commercial grade lead silicate $(1.75 \mathrm{phr})$ and lead stearate $(0.25 \mathrm{phr})$ were used as a stabilizer and lubricant respectively $(\mathrm{phr}=$ parts per hundred parts of resin). Cholesterol, cholesteryl chloride, and cholesteryl benzoate (Aldrich Chemical Co. UK) were used as delivered.

\section{Preparation of Films}

Thin films (about $0.2 \mathrm{~mm}$ thick) were solution cast by dissolving PVC and an appropriate amount of the additive in tetrahydrofuran. In all cases, transparent films were obtained, indicating the compatibility of additives at these concentrations with

\footnotetext{
* To whom proofs and correspondence should be sent.
} 
PVC. These compositions were therefore used for compression moulding of films as follows: a mixture of PVC powder, stabilizer, lubricant and the cholesteryl additive $(2-7 \mathrm{phr})$ was hot blended at $130^{\circ} \mathrm{C}$ for $10 \mathrm{~min}$, roll-milled at $165^{\circ} \mathrm{C}$ for $7 \mathrm{~min}$, and then compression moulded into sheets of $20 \times 20 \times 0.05$ $\mathrm{cm}$ dimensions. All samples were annealed at $60^{\circ} \mathrm{C}$ for one week. Samples were cut in $63 \mathrm{~mm}$ diameter discs for dielectric studies and in $10 \times 19 \mathrm{~mm}$ strips for dynamic mechanical measurements.

\section{Dielectric Measurements}

Dielectric measurements were carried out on a Schering bridge of Rohde and Schwarz at 10 frequencies in the range 0.5 to $200 \mathrm{kHz}$. At each frequency, the measurements were conducted in the range from $55^{\circ} \mathrm{C}$ to $130^{\circ} \mathrm{C}$ covering only the $\alpha$ relaxation region of $\mathrm{PVC}$.

Specimens were clamped between polished stainless steel electrodes of guarded electrode cell assembly. The holder assembly was immersed in a thermostated oil bath whose temperature could be controlled to within $\pm 0.05^{\circ} \mathrm{C}$. Two thermocouples were embedded in the electrode for monitoring the sample temperature, and the thermo-e.m.f. was read on a digital microvoltmeter. The cell was maintained for $30 \mathrm{~min}$ at the desired temperature before taking the readings. Capacitance and $\tan \delta$ were measured at the set temperature for all required frequencies. Following completion of the measurements, sample thickness was measured at room temperature. From the thickness and calibrated values of the air capacitance of the cell, $\varepsilon^{\prime}$ and $\varepsilon^{\prime \prime}$ were calculated.

\section{Dynamic Mechanical Analysis (DMA)}

Dynamic mechanical measurements were made on a Du Pont DMA-981 instrument. For storage modulus measurements, the samples were clamped in the vertical mode. To improve the sensitivity, the samples were mounted in the horizontal mode for damping measurements; in this case, however, the absolute storage modulus could not be evaluated. Measurements were made in the temperature range from -120 to $+110^{\circ} \mathrm{C}$ at a heating rate of $5^{\circ} \mathrm{C}$ $\min ^{-1}$ and a $2.51 \mathrm{~min}^{-1}$ flow rate of $\mathrm{N}_{2}$. The amplitude of oscillations used was $0.2 \mathrm{~mm}$ peak to peak. The plots on an $X-Y-Y^{\prime}$ recorder gave the resonant frequency $(f, \mathrm{~Hz})$ of the sample and damping $(V, \mathrm{mV})$ versus temperature of the sample. The instrument was calibrated using standard samples of poly(methyl methacrylate) and poly(carbonate) supplied by the manufacturer. From the recorder plots, at very closely spaced points, $E^{\prime}$ and $\tan \delta$ were calcualted as follows:

$$
\begin{gathered}
E^{\prime}=\frac{\left(4 \pi^{2} f^{2} J-K\right)}{2 W\left(\frac{L}{2}+D\right)^{2}}\left(\frac{L}{T}\right)^{3} \\
\times\left[1+0.71\left(\frac{2 T}{L}\right)^{2}-0.1\left(\frac{2 T}{L}\right)^{3}\right] \\
\tan \delta=C \cdot V / f^{2} \\
E^{\prime \prime}=E^{\prime} \cdot \tan \delta
\end{gathered}
$$

where $J$ is the moment of inertia of the system; $K$, the pivot spring constant; $L, T$, and $W$, the sample length, thickness and width (m); $D$, the clamping distance (m); and $C$, the damping constant. Values of $(\tan \delta)_{\max }$ are given in Table I.

\section{RESULTS}

Dielectric loss versus temperature data at few selected frequencies are given in Figures 1-3. From the data of $\tan \delta$ versus temperature at each frequency $(f)$ constants $a, b$, and $c$ in eq 4 were evaluated by regression analysis:

$$
\begin{aligned}
\ln \tan \delta= & \ln \tan \delta_{\mathrm{m}}+a\left(T-T_{\mathrm{m}}\right) \\
& +b\left(T-T_{\mathrm{m}}\right)^{2}+c\left(T-T_{\mathrm{m}}\right)^{3}
\end{aligned}
$$

where $T_{\mathrm{m}}$ is the temperature at which the $\tan \delta-T$ curve shows a maximum. Data for $f_{\mathrm{m}}$ and $T_{\mathrm{m}}$ were used to obtain $f_{\mathrm{m}}$ at a reference temperature $T_{0}$ of the Williams-Landel-Ferry (WLF) equation ${ }^{4}$

$$
\log a_{\mathrm{T}}=\frac{-C_{1}\left(T-T_{0}\right)}{C_{2}+\left(T-T_{0}\right)}
$$

where $a_{\mathrm{T}}$ is the shift factor and $C_{1}$ and $C_{2}$ are constants related to the free volume. The plot of shift factor $\log a_{\mathrm{T}}$ versus $\left(T-T_{0}\right)$ is shown in Figure 4. The dotted line corresponds to the WLF equation with the universal WLF constants $C_{1}=8.86, C_{2}=$ 101.6; the solid line corresponds to the fitting of our experimental data on pure PVC for which the constants obtained are $C_{1}=4.72, C_{2}=61.83$ by setting $T_{0}=T_{\mathrm{g}}+50=400 \mathrm{~K}$. With these values of $C_{1}$ and $C_{2}$ for systems PVC + cholesterol, PVC + cholesteryl chloride, and PVC + cholesteryl ben- 
zoate, $T_{0}$ at each concentration were evaluated for the best fit of the data by regression analysis.

From the WLF equation, the apparent enthalpy of activation $\Delta H_{\mathrm{a}}$ is obtained as

$$
\Delta H_{\mathrm{a}}=2.303 R \cdot C_{1} \cdot C_{2} T^{2} /\left[C_{2}+\left(T-T_{0}\right)\right]^{2}
$$

Since $\Delta H_{\mathrm{a}}$ rapidly decreases with temperature in the region $T>T_{0}$, for the sake of comparison of $\Delta H_{\mathrm{a}}$ for different systems, we have given $\Delta H_{\mathrm{a}}$ at $\left(T_{0}-25\right)^{0}$ in Table I.

Table I gives the glass transition temperatures $T_{\mathrm{g}}$ for these systems measured on a thermomechanical analyser (TMA) at a heating rate of $8^{\circ} \mathrm{C} \min ^{-1}$. By setting $T_{\mathrm{m}}=0$ eq 4 can be used for regression analysis of the data $\varepsilon^{\prime}$ versus temperature to obtain $\varepsilon_{0}$ and $\varepsilon_{\infty}$. The dielectric strength, $\Delta \varepsilon^{\prime}$, is defined as $\varepsilon_{0}-\varepsilon_{\infty}$. Together with these values and the measured area of the curve $\tan \delta$ versus $(1 / T)$, the enthalpy of activation was calculated from the relation ${ }^{5}$ :

$$
\Delta H_{\mathrm{a}}=\frac{\pi R \cdot \varepsilon^{\prime}}{2\left(\varepsilon_{0} \cdot \varepsilon_{\infty}\right)^{1 / 2} \int \tan \delta \mathrm{d}(1 / T)}
$$

$\Delta H_{\mathrm{a}}$ calculated from eq 7 agreed well with that given in Table I and are not given here.

The temperature maximam for $\alpha$ - and $\beta$ - relaxation peaks in the DMA measuements were read

\begin{tabular}{|c|c|c|c|c|c|c|c|c|c|}
\hline & \multirow{2}{*}{$\begin{array}{l}T_{\mathrm{g}}{ }^{\circ} \mathrm{C} \\
\text { (from } \\
\text { TMA) }\end{array}$} & \multicolumn{2}{|c|}{ Dielectric (at $1 \mathrm{kHz}$ ) } & \multirow{2}{*}{$\frac{\left(T_{0}-50\right)}{{ }^{\circ} \mathrm{C}}$} & \multirow{2}{*}{$\begin{array}{c}\begin{array}{c}\Delta H_{\mathrm{a}} \text { at } \\
\left(T_{0}-25\right)^{\circ} \mathrm{C}\end{array} \\
\mathrm{kJ} \mathrm{mol}^{-1}\end{array}$} & \multicolumn{2}{|c|}{ DMA } & \multicolumn{2}{|c|}{ DMA $(\tan \delta)_{\mathrm{m}}$} \\
\hline & & $T_{\mathrm{m}} /{ }^{\circ} \mathrm{C}$ & $(\tan \delta)_{\mathrm{m}}$ & & & $T_{\alpha} /{ }^{\circ} \mathrm{C}$ & $T_{\beta} /{ }^{\circ} \mathrm{C}$ & $(\alpha)$ & $(\beta)$ \\
\hline Pure PVC & 77.0 & 102.3 & 0.1255 & 77 & 579.5 & 95 & -10 & 1.2 & 0.02880 \\
\hline PVC + Cholesterol & $\begin{array}{l}3 \mathrm{phr} 78.0 \\
5 \mathrm{phr} 76.1 \\
7 \mathrm{phr} 74.2\end{array}$ & $\begin{array}{l}91.6 \\
90.25 \\
89.55\end{array}$ & $\begin{array}{l}0.1723 \\
0.1434 \\
0.1147\end{array}$ & $\begin{array}{l}63 \\
61 \\
58\end{array}$ & $\begin{array}{l}537.1 \\
531.2 \\
522.3\end{array}$ & $\begin{array}{l}91.4 \\
90.0 \\
91.2\end{array}$ & $\begin{array}{l}-23 \\
-24 \\
-26\end{array}$ & $\begin{array}{l}1.41 \\
1.65 \\
1.85\end{array}$ & $\begin{array}{l}0.0180 \\
0.01663 \\
0.0153\end{array}$ \\
\hline 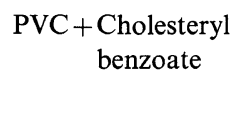 & $\begin{array}{l}2 \mathrm{phr} 79.0 \\
4 \mathrm{phr} 77.2 \\
6 \mathrm{phr} 76.5\end{array}$ & $\begin{array}{l}94.25 \\
93.25 \\
92.45\end{array}$ & $\begin{array}{l}0.1396 \\
0.1135 \\
0.1529\end{array}$ & $\begin{array}{l}70 \\
67 \\
64\end{array}$ & $\begin{array}{l}558.1 \\
549.0 \\
540.0\end{array}$ & $\begin{array}{l}91.0 \\
89.17 \\
87.0\end{array}$ & $\begin{array}{l}-15.2 \\
-18.00 \\
-21.8\end{array}$ & $\begin{array}{l}1.15 \\
1.2 \\
1.05\end{array}$ & $\begin{array}{l}0.0145 \\
0.0140 \\
0.0125\end{array}$ \\
\hline 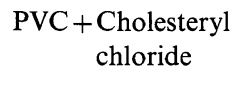 & $\begin{array}{l}2 \mathrm{phr} 69.0 \\
4 \mathrm{phr} 64.0 \\
6 \mathrm{phr} 61.0\end{array}$ & $\begin{array}{l}92.1 \\
90.0 \\
86.45\end{array}$ & $\begin{array}{l}0.1550 \\
0.1480 \\
0.1490\end{array}$ & $\begin{array}{l}62 \\
60 \\
57\end{array}$ & $\begin{array}{l}538.5 \\
532.5 \\
523.6\end{array}$ & $\begin{array}{l}89.6 \\
87.1 \\
85.0\end{array}$ & $\begin{array}{l}-16.5 \\
-21.9 \\
-31.3\end{array}$ & $\begin{array}{l}1.8 \\
1.85 \\
1.96\end{array}$ & $\begin{array}{l}0.0390 \\
0.03625 \\
0.02850\end{array}$ \\
\hline
\end{tabular}

Table I. Dielectric and dynamic mechanical behaviour of PVC + additive systems

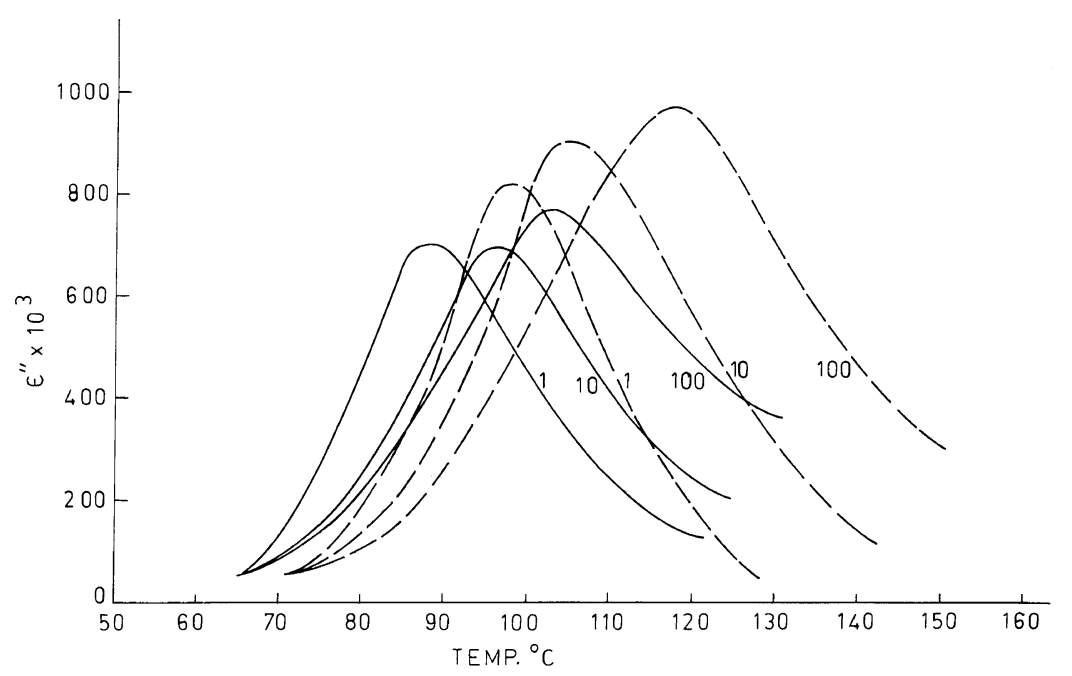

Figure 1. Dielectric loss versus temperature plots for pure PVC (dotted line curves) and PVC $+(7 \mathrm{phr})$ cholesterol (solid line curves) at $1 \mathrm{kHz}, 10 \mathrm{kHz}$, and $100 \mathrm{kHz}$. 
from the direct $X-Y-Y^{\prime}$ recorder plots and are given in Table I as $T_{\alpha}$ and $T_{\beta}$ temperatures.

Plots of storage modulus $E^{\prime}$ and $\tan \delta v s$. temperature are given in Figures 5-7.

\section{DISCUSSION}

From the results in Table I, it is evident that glass transition temperatures $T_{\mathrm{g}}$ for polymer $+\mathrm{Ch}$ (2 $\mathrm{phr}) / \mathrm{ChBz}(2 \mathrm{phr})$ are slightly higher than $T_{\mathrm{g}}$ of pure PVC. For other concentrations and for $\mathrm{PVC}+\mathrm{ChCl}$, however, these values are lower than $T_{\mathrm{g}}$ of pure PVC. $T_{\alpha}$ temperatures obtained from DMA measurements for all systems are higher than corresponding $T_{\mathrm{g}}$ by about $10-15^{\circ} \mathrm{C}$. Such differences have been reported earlier ${ }^{6}$ for other systems. $T_{\alpha}$ for PVC + additive systems are lower than $T_{\alpha}$ for pure PVC. It may also be noted that the values of

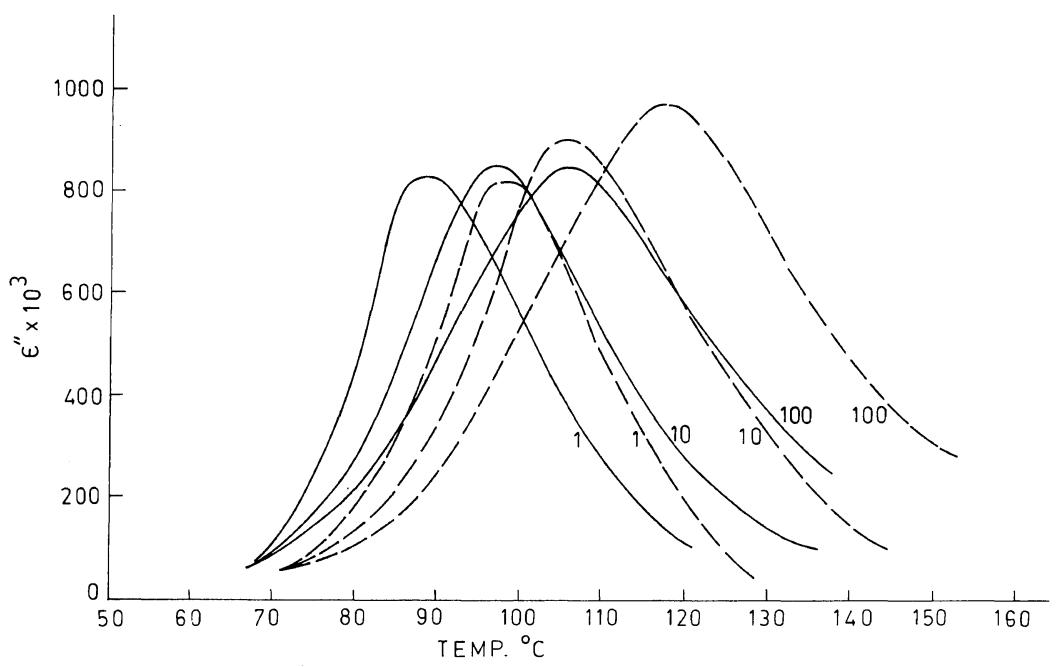

Figure 2. Dielectric loss versus temperature plots for pure PVC (dotted line curves) and PVC $+(6 \mathrm{phr})$ cholesteryl benzoate (solid line curves) at $1 \mathrm{kHz}, 10 \mathrm{kHz}$, and $100 \mathrm{kHz}$.

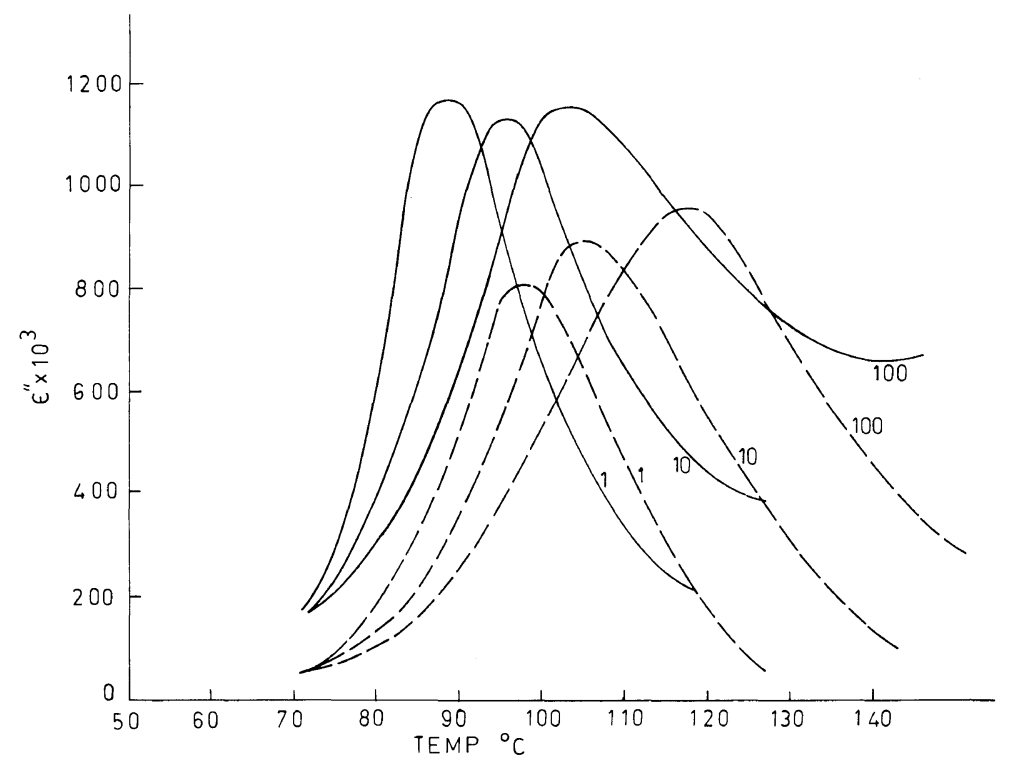

Figure 3. Dielectric loss versus temperature plots for pure PVC (dotted line curves) and PVC $+(6 \mathrm{phr})$ cholesteryl chloride (solid line curves) at $1 \mathrm{kHz}, 10 \mathrm{kHz}$, and $100 \mathrm{kHz}$. 
Dielectric and Dynamic Mechanical Behaviour of PVC Containing, $\mathrm{Ch}, \mathrm{ChCl}$, and $\mathrm{ChBz}$

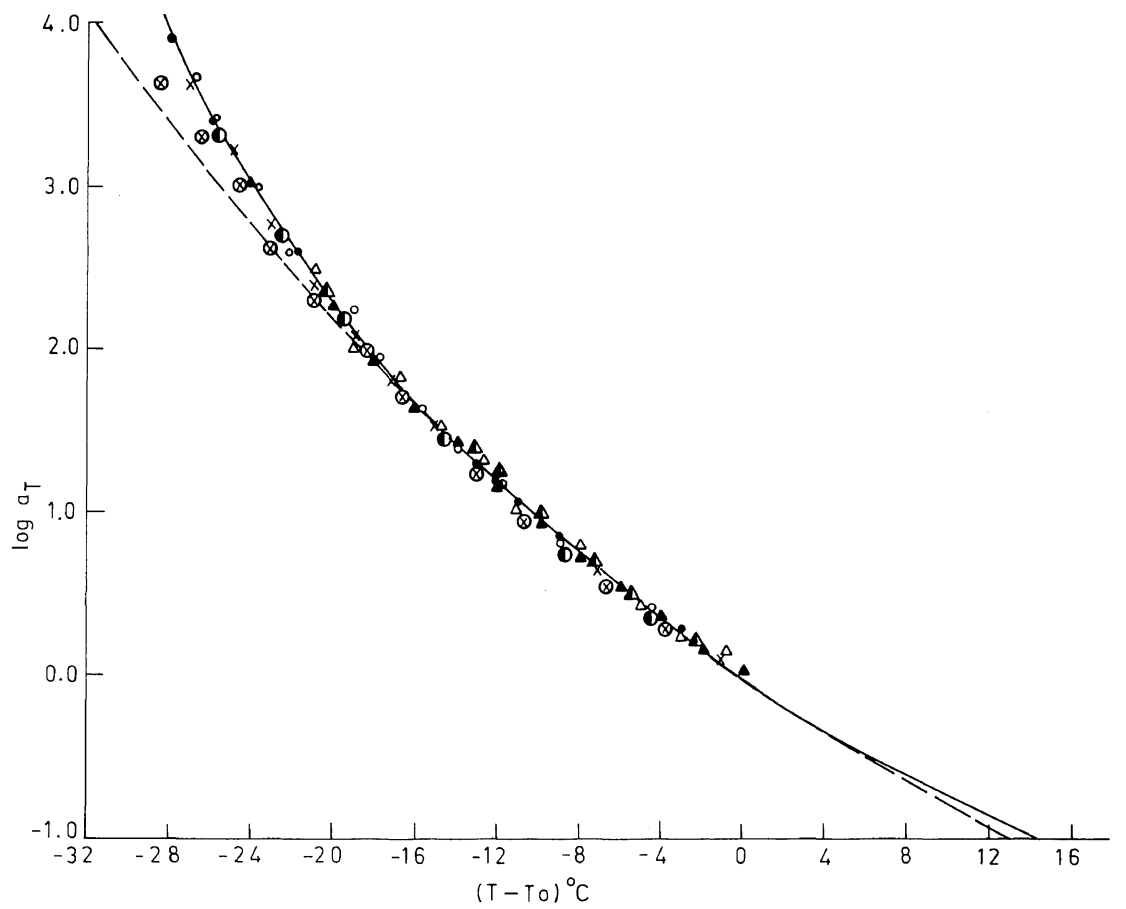

Figure 4. WLF universal curve (dotted line) and WLF curve fitted for pure PVC (solid line) experimental points for $\mathrm{PVC}+$ additives, cholesterol $(\triangle, 3 ; \boldsymbol{\Delta}, 5 ; \Delta, 7 \mathrm{phr})$ cholesteryl chloride $(\otimes, 4 \times 6 \mathrm{phr})$ and cholesteryl benzoate $\boldsymbol{D}, 2 ; 0,4 ; \bigcirc, 6 \mathrm{phr})$.

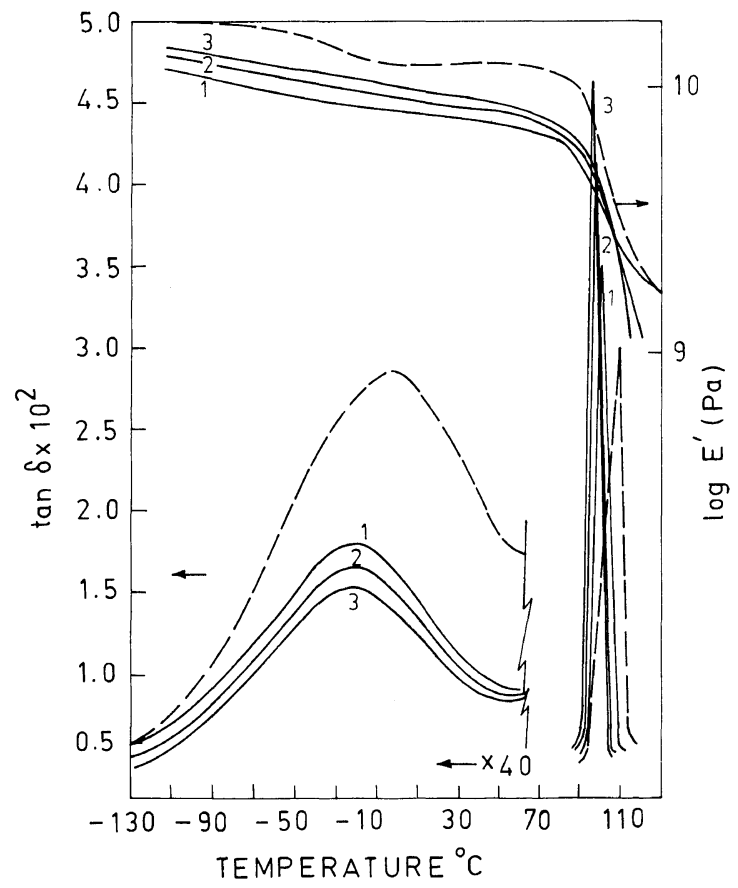

Figure 5. DMA plots for $E$ and $\tan \delta$ versus temperature for pure PVC (dotted line curve) and PVC+cholesterol (solid line curves) $1,3 \mathrm{phr} ; 2,5 \mathrm{phr} ; 3,7 \mathrm{phr}$. 
D. D. Deshrande and V. K. Tiwari

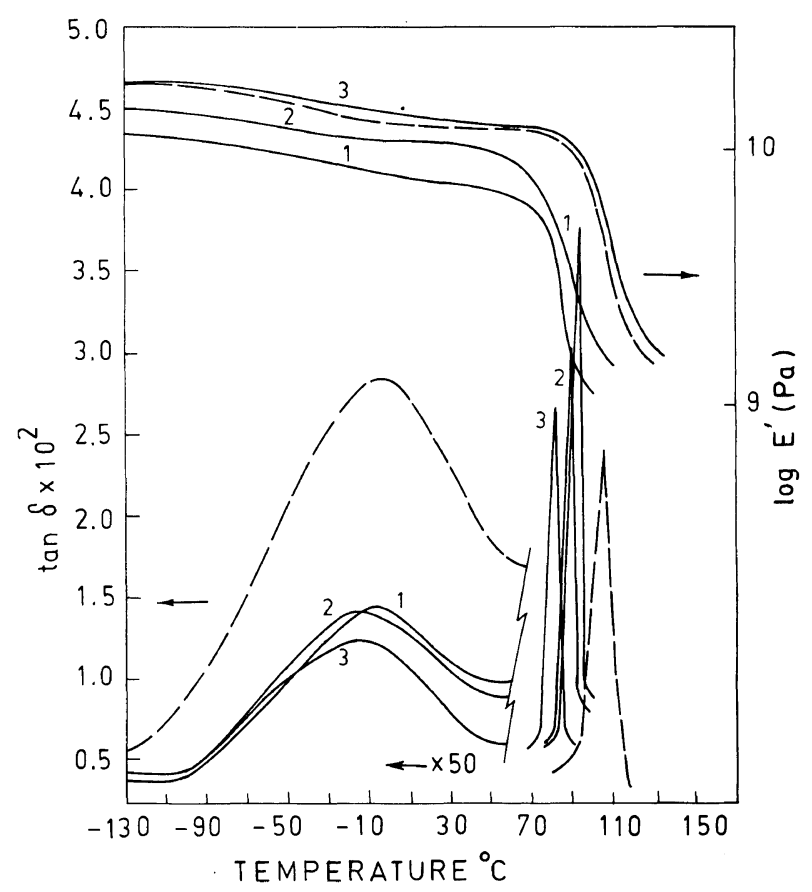

Figure 6. DMA plots for $E^{\prime}$ and $\tan \delta$ versus temperature for pure PVC (dotted line curve) and PVC + cholesteryl benzoate (solid line curves) 1, $2 \mathrm{phr} ; 2,4 \mathrm{phr} ; 3,6 \mathrm{phr}$.

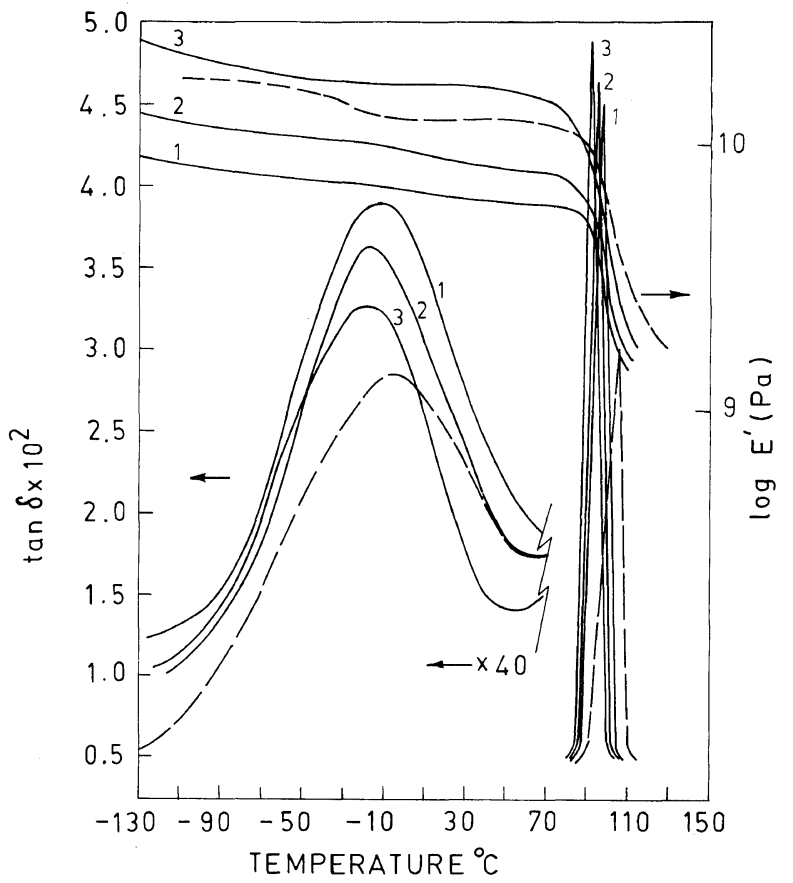

Figure 7. DMA plots for $E$ and $\tan \delta$ versus temperature for pure PVC (dotted line curve) and PVC + cholesteryl chloride (solid line curves) 1, 2 phr; 2, 4 phr; 3, 6 phr. 
$\left(T_{0}-50\right)$ for all systems are very close to $T_{\mathrm{g}}$ of the system under consideration because of $T_{0}=$ $\left(T_{\mathrm{g}}+50\right)$ in the WLF relationship. From Figures $1-3$ and $5-7$, it can be seen that all loss curves have shifted to low temperatures by the addition of cholesterol, cholesteryl chloride and cholesteryl benzoate. Both the dielectric and DMA measurements show that the shift to low temperatures and the broadening increase with increasing concentration of additives. Thus, the addition of small molecules - though highly crystalline in nature- to PVC has an overall effect of increasing segmental mobility. We could not use higher concentrations of these additives owing to their limited solubilities in PVC. The intensities of the $\alpha$-peaks in both the dielectric loss $\left(\varepsilon^{\prime \prime}\right)$ and DMA tan $\delta$ curves for PVC+additive systems are higher than that in pure PVC and decrease with increasing amount of additive.

For pure PVC, the $\beta$-relaxation occurs at about $-10^{\circ} \mathrm{C}$ and is very weak in intensity. For this reason, DMA measurements were conducted with samples mounted in the horizontal mode. $T_{\beta}$ temperatures shift to low temperatures with increasing additive concentration. The $\beta$-peaks for PVC + cholesterol and PVC + cholesteryl benzoate have much lesser intensities than those in pure PVC (see Figures 5,6 ). Such a decrease in intensity of a $\beta$ peak or virtual suppression of the peak in some cases has been regarded as an antiplasticization effect. $^{7,8}$ It has been argued $^{9}$ that the additives which normally act as plasticizers for PVC behave as antiplasticizers when used in very small amounts $(<10 \%)$. In the present systems viz. PVC + cholesterol and PVC + cholesteryl benzoate, a specific interaction between the $\mathrm{C}-\mathrm{Cl}$ dipole of $\mathrm{PVC}$ and the $\mathrm{OH}$ group from cholesterol or the aromatic protons from cholesteryl benzoate is possible, and this may be responsible for the lowering of the $\beta$-peak intensity. This situation did not occur in the PVC + cholesteryl chloride systems. In the three systems, the storage modulus in the glassy region is less than that in pure PVC and increases with increasing additive concentration.
Thus, dielectric and DMA measurements indicated the plasticizing effect of crystalline additivescholesterol, cholesteryl benzoate, and cholesteryl chloride. These observations are not in line with those on systems consisting of PVAc and PBMA with the same additives and in which antiplasticization was observed. The main difference in these systems arises from rigid $\mathrm{C}-\mathrm{Cl}$ dipoles attached to the main chain in the case of PVC, while the ester group dipoles in PVAc and PBMA are in the pendant group and are much more flexible. Thus, the activation energy for the $\alpha$-relaxation in PVC is much higher $\left(\approx 448 \mathrm{~kJ} \mathrm{~mol}^{-1}\right)$ than that in either $\operatorname{PVAc}^{1}\left(\approx 272 \mathrm{~kJ} \mathrm{~mol}^{-1}\right)$ or in $\mathrm{PBMA}^{2}(\approx 123 \mathrm{~kJ}$ $\left.\mathrm{mol}^{-1}\right)$. Hence, an additive molecule which can easily hinder the segmental motion in PVAc or PBMA would not be able to do so in the case of $\mathrm{PVC}$ unless there is a very strong specific interaction between the additive and the monomeric units of PVC.

Acknowledgement. We are thankful to the Department of Atomic Energy (Government of India) for providing financial support for this work.

\section{REFERENCES}

1. D. D. Deshpande and N. R. Kandasamy, Symposium on Industrial Polymers and Radiation, D.A.E., 1979, p 336.

2. D. D. Deshpande and N. R. Kandasamy, Polymer, 22, 1211 (1981).

3. N. R. Kandasamy, Ph. D. Thesis, I.I.T. Bombay (1980).

4. M. L. Williams, R. F. Landel, and J. D. Ferry, J. Am. Chem. Soc., 77, 3701 (1955).

5. B. E. Read and G. Williams, Trans. Faraday Soc., 57, 1979 (1981).

6. N. A. Shah, Ph. D. Thesis, Sardar Patel University, Gujarat, India (1982).

7. H. Bertilsson and J. F. Jansson, J. Macromol. Sci. Phys., B14, 251 (1977).

8. M. Pizzoli, G. Pezzin, and G. Ceccorulli, J. Macromol. Sci. Phys., B14, 241 (1977).

9. R. F. Boyer, "Polymeric Materials," The American Society of Metals, 1975, Chapter 6. 